\title{
The Predictive Power of Psychological Needs and Self-efficacy for the Level of Marital Happiness
}

\author{
Fadia Aied Al-Smeheen ${ }^{1}$ \\ ${ }^{1}$ Department of Counseling and Mental Health, The World Islamic Science \& Education University, Jordan \\ Correspondence: Fadia Aied Al-Smeheen. E-mail: fadia_a2013@yahoo.com
}

Received: August 23, 2020

Accepted: October 13, 2020

Online Published: October 31, 2020

doi:10.5539/ass.v16n11p41

URL: https://doi.org/10.5539/ass.v16n11p41

\begin{abstract}
This study aimed at identifying the most common psychological needs among wives, identifying the degree of self-efficacy and the level of martial happiness among the study sample individuals as well as identifying the extent to which these psychological needs contribute to predicting the level of marital happiness. The study consisted of (150) married female lawyers. To succeed the study objectives, the scale of psychological needs was developed; it consisted of (20) items that measure four basic dimensions: psychological security, the need to achievement, the need to affiliation, and need to respect. The scale of self-efficacy (Schwarzer \& Jerusalem, 1995) was used, and the scale of marital happiness was developed; it consisted of (40) items that measure five main dimensions: emotional adjustment, intellectual adjustment, family adjustment, social adjustment, and economic adjustment.

The study results directed that the most common psychological need among wives is the need to achievement. The results revealed that the level of self-efficacy among the study sample individuals was medium. The results showed that the level of marital happiness among the married Jordanian female lawyers was medium for the total degree and each of the following dimensions (emotional adjustment, economic adjustment, intellectual adjustment, social adjustment), while the dimension of family cohesion was of a high degree. The results revealed that there is a predictive power for the psychological needs and self-efficacy concerning the level of marital happiness.

In the light of the results, the study recommended the necessity of conducting further experimental researches in the domain of self-efficacy and marital happiness by developing counseling programs to improve these variables among spouses.
\end{abstract}

Keywords: psychological needs, self-efficacy, marital happiness

\section{Introduction}

Some studies and researches focused on the negative aspects of the individual's life, such as anxiety, depression and emotional disorders at the expense of the positive domains. However, recently, imbalance in this context has been addressed, where several studies and domains related to self psychological health were conducted. A dependent research domain called positive psychology came to the surface and was particularly dedicated to understanding the process of human happiness among individuals (Mahmoud \& Yassin, 2019).

The most important concepts in positive psychology are related to Subjective wellbeing and Happiness. Each one of these concepts expresses self well-being, positive emotions, life satisfaction, finding meaning in life and satisfaction. The individual's assessment to his life includes cognitive and emotional aspects as well as personality aspects (Denizli, Cankaya, \& Cihanger, 2020).

(Homead, 2019) suggested that (happiness) is one of the psychological concepts that involved more attention by the researchers in the domain of psychology and psychological health, considering that attaining happiness is an important indicator concerning the individual's adaptation and psychological health; it represents an objective that the individual hopes to achieve. (Kamp Dush et al., 2008) suggested that the levels of high happiness reduce the incidence of depressive symptoms among individuals.

Psychologists used several concepts and terms when studying and measuring the concept of happiness, such as (sense of well-being, life satisfaction, psychological welfare). All these expressions include the cognitive and perceptual assessment for all the aspects of life requirements (Cakir \& Demirel, 2019). In this context, (Wilson) 
is considered as one of the pioneers who wrote about the topic of happiness, where he viewed the happy individual as the one who has such characteristics as being pessimistic and self-confident (Al-Alwan, 2006). (Argle, 1997) suggested that happiness can be viewed as a reflection of the degree of life satisfaction, or as a reflection for the frequent incidence of pleasant emotions and that the concept of happiness includes life satisfaction with all its domains.

According to Freud, attaining happiness comes through love and job, considering them as basic elements of happiness, where they are closely related with each other. Rogers argued that happiness is a marginal conclusion or secondary result of psychological maturity instead of being an objective (Al-Nayal \& Ali, 1995).

(Ryff \& Singer, 2008) criticized the prevailing conceptualization of happiness of only being the good feeling, tranquility and satisfaction, and performed a comprehensive analytical review of the human and existential philosophies. They determined basic dimensions of happiness: self-acceptance, positive relationships with others, personal growth, purpose in life, environmental mastery.

In his study, (Lee, 2020) referred to Plato's concept, where the wisest and fairest person, who has the ability to manage his anger and has virtues, is the one who is worthy to be happy. (Veenhoven, 2001) suggested that happiness is represented by the degree at which the individual positively make judgments about the quality of his current life, his enjoyment in it based on his personal estimations and provisions.

In his definition of happiness, Demirel (2019) confirmed that happiness is the state of internal peace, positive feelings and life satisfaction. Happiness can be measured based on several criteria, including the prevailing values of the individual, his temper, and the surrounding conditions, which affect his feelings of happiness satisfaction (Diener, 2019). Easterlin (2001) suggested that happiness is based on comparison between the social, financial or cultural aspects on the one hand, and what has been accomplished in reality on the other hand. Comparison is not exclusive for the individuals in a certain community; therefore, the levels of happiness differ based on the social and economic standards.

(Chaing, 2010) suggested that happiness results from the successful solving of several marital, social and psychological crises facing the individual throughout his life span.

(Khodarahimi, 2015) suggested that healthy marriage has a long term positive effect on marital happiness, where adjustment between spouses increases the degree of happiness in general.

Recently, there has been increasing attention in studying the level of happiness among spouses, where specific scales were developed about marital happiness in the light of the personal, social and psychological demographic variables related to achieving happiness among individuals (Weinstein et al., 2010). The happy marriage is mainly based on harmony between spouses, where the personal and psychological standards criteria as well as mutual respect match amongst spouses Abbas (2013). (Kumar, 2015) suggested that the successful marriage effectively contributes to the achievement of personal adjustment due to the happiness, optimism and life satisfaction that are achieved for the individual.

(Onen et al., 2014) suggested that using the term "marital happiness" refers to the process of assessing marital quality and marital life in order to achieve more marital satisfaction. Marital happiness is defined as the extent to which spouses accept their marital life and the satisfaction of each one with the nature of mutual interaction between them in the different life domains; it is related to the spouses' acceptance for the individual differences between them (Camisasca, Miragoli, \& Blasio, 2014).

(Kalatbari et al., 2013) suggested that happiness is related to the degree of satisfaction and agreement among spouses about the basic issues in their life, such as family and financial issues as well as life philosophy.

(Chen, Tanaka, Uji, Hiramura, \& Shikai, 2007) suggested that achieving happiness in marriage entails the ability to be committed to the requirements of marital life, including: keeping communication channels open, expressing one's feelings, as well as sharing experiences, interests and values. Marital happiness expresses an internal sensation consisting of positive feelings that reflect marital satisfaction, which is also reflected on the behavior and personality of spouses in the form of a harmonious family life, whose effect extends to include all the individuals (Ismail, 2015).

Marital happiness is not an individual issue or an imagination that cannot be achieved, but it is a necessity in life that is mainly based on intimacy. In such a life, responsibilities are mixed in a nice harmony, where there is no authoritative power in practicing rights or inaction in performing tasks and duties (Suleiman, 2005).

Muraru and Turliuc, 2013 suggested that marital happiness doesn't require too much, where spouses only need to have a certain degree of independence in their marital life, the ability to understand and respect the other spouse, 
transparency and faith in marital relationship, as well as the ability of each one of them to satisfy each other and solve problems wisely and thoughtfully.

The dimensions of marital happiness:

Marital happiness includes a number of economic, social, familial and psychological dimensions that integrate with each other in order to achieve happiness. These dimensions include:

First, psychological and emotional adjustment. Emotional adjustment between spouses entails expressing love, understanding, respect and the ability to give. Also, emotional adjustment considerably contributes to providing comfort and tranquility amongst spouses which would, in turn, achieve marital happiness (Pasch \& Bradbury, 1998).

Second, family Cohesion. This dimension includes family stability, where the mutual respect prevails among spouses and with children. This dimension entails the ability to achieve family requirements and solve family problems effectively and constructively (Yamina, 2012). Family cohesion is achieved by the emotional conversion between the family individuals in life issues as well as developing healthy communication styles (Shigeto et al., 2014).

Third, social adjustment. It is defined as the individual's ability to establish good relationships with others, where these relationships are characterized by the ability to afford responsibility and recognize the importance of others (Al-Kandari, 2005). It also includes the feeling of comfort and happiness during interaction with others as well as the interest in gaining their respect by establishing constructive social relationships in the light of the customs and traditions prevailing in the community (Bosisini, 2011).

Fourth, Economic adjustment. It is represented by an agreement between spouses about the issues related to managing family funding and monthly budget (Yamina, 2012). Kinnunen and Feldt (2004) suggested that low income and unemployment are considered as important factors in formulating a series of psychological stressors; therefore, economic conditions rise the psychological anguish which negatively affects the level of marital happiness. (Furdyna et al., 2008) submitted that the individual's level of happiness is affected by income.

Achieving happiness depends on Maslow hierarchy in satisfying needs starting from the lowest physiological needs to the highest needs represented by self-actualization; since the individual seeks to achieve his objectives in order to have the feeling of happiness and satisfaction (Al-Osh). Therefore, we will study what is known as the psychological needs.

\subsection{Psychological Needs}

Recognizing the psychological needs and the motives, objectives as well as healthy and unhealthy behaviors related to them is an important topic in the domain of psychological health. Through studying the psychological needs and their nature, we can understand the personality and interpret the human behavior (Al-Jaberi, 2012). Needs are defined as a state of internal unbalance that leads to a feeling of anxiety and stress, which motivates the individual to do activities to achieve internal balance and reduce the anxious feelings (Ebersold \& Rahm, 2019).

(Al-Rashidi \& Al-Otaibi, 2011) suggested that needs represent the judgment that the individual makes about what is required to a certain valuable objective; achieving this objective leads to an internal experience called satisfaction. Deci and Rayan, 2001 suggested that the personal and environmental factors represent basic determinants to satisfy the psychological needs. Also, satisfying the psychological needs represented by independence, affiliation and efficacy leads to creating integration in the individual's personality. (Froiland et al., 2019) suggested that achieving the psychological needs is a basic requirement to understand the human nature and an important condition to achieve happiness. Therefore, it is important to address the individual's needs stemming from the conditions of his existence.

The theories interpreting psychological needs:

\section{First, Need-Hierarch Theory for Maslow}

Maslow's theory is considered as one of the most famous theories in interpreting needs, in that he set a hierarchical series consisting of five levels of basic needs' system, these are (Al-Jaberi, 2012):

1- The physiological needs. They represent the hierarchy base in Maslow's system, as they are related to the needs of survival, such as eating and drinking.

2- Safety needs. These needs are represented by the individual's desire to be protected against danger and threat. Their manifestations include avoiding pain, freedom from fear, looking for stability. 
3- Love and belonging needs. They refer to the individual's desire of belonging, interaction with others as well as making friendships and establishing social relationships.

4- Self-esteem needs. These needs include self-confidence, being respected by others. Their manifestations are represented by social acknowledgement and prestige.

Second, interpreting Murray's theory of psychological needs. Murray's theory confirmed that needs are the basic pillar for the theory of motives. Needs are defined as the power that organizes perception, thinking and awareness among individuals (Ford et al., 2019). The theory is interested in the physiological processes accompanying the psychological processes, where they are temporally and functionally related with the psychological processes (Maamari \& Khaladi, 2014). Murray suggested that the concept of need in manifested by the impact of behavior and the final conclusion. Also, the used pattern to achieve the behavior, the elective attention and the expression of happiness satisfaction represent an important indicator to achieve needs (Zhang \& Whitebread, 2019).

Murray suggested a list of psychological needs, including: first, the need to achieve, which means the internal desire to do the difficult tasks as well as the individual's ability to overcome weaknesses and face challenges successfully. Second, the need of independence, which means the individual's need to get free from the restrictions that limit his powers and innovations. Third, the need of control, which refers to the individual's disposition to control the events taking place around him. Fourth, the safety need, which refers to the individual's need to resist humiliation, blaming and criticism (Al-Rashidi \& Al-Otaibi, 2011).

\subsection{Social Efficacy}

This concept represents a basic pillar in the Social Cognitive Theory, which confirms the individual's ability to control his behavior based on his beliefs, and personal expectations; individuals have a specific system of self-beliefs that expresses the cognitive perception of personal abilities, which enables them to do tasks effectively and control the environmental variables via the adaptation methods in facing the possible problems (Girgin, 2020). Self-efficacy is one of the basic elements of learning; it refers to the individual's ability to make judgment about his efficacy in doing tasks, where the individual's efficacy represents a cognitive mirror that reflects his potentials (Kaygisiz et al., 2020). The individuals' recognition of their self-efficacy affects the types of the future plans that they set, in terms of the possibility of success or failure (Bagci \& Unveren, 2020).

(Zimmerman, 2000) suggested that the concept of self-efficacy refers to the individual's perception to his abilities in implementing and achieving tasks to reach the desired performance. Self-efficacy is also defined as a set of expectations that are based on the previous life experiences which, in turn, affect the levels of performance in the new situations (Uygur \& Yanpar Yelken, 2020). (Erol et al., 2019) defined self-efficacy as the individual's ability to organize and manage his performance, control it in certain situations and achieve the desired objectives. Self-efficacy contributes to determining the individual's expected behavior and the amount of exerted power in facing challenges (Fitriani et al., 2020).

The resources of self-efficacy: There are four resources through which self-efficacy is acquired. According to (Bandura, 1997), they are:First, procedural achievements. They constitute the experiences of success and failure that the individuals experienced in the past. The procedural achievements are considered as the most influential resources in self-efficacy, where they depend on the real experience that the individual has. Second, vicarious experiences. The individual views his abilities in the light of the experiences of others. The consist of the alternative experiences based on his observations of failure and success experiences that others experienced in similar situations; people don't depend on the procedural achievements as the only source of information. Third, verbal persuasion. It means informing the individual by others that he is able or not able to accomplish a certain task. Verbal persuasion could be the weakest variable affecting self-efficacy, depending on the persuading person.

Bandura confirmed that there are two types of expectations that are related to the concept of self-efficacy. First, the expectations related to self-efficacy; these are related to the individual's perception of his ability to do a certain behavior. These expectations enable the individual to determine the degree of his efficacy and the required effort to do the task. Second, the expectations related to results, which refer to the individual's belief that performing a certain behavior leads to achieving certain results. Therefore, the nature of the relationship is clearly determined, when determining the appropriate behavior to do a certain task and the expected results of the behavior (Yilmaz \& Turan, 2020).

(Cam, Eskisu, \& Kardas et al., 2020) suggested that self-efficacy is primarily determined by the difficulty of situations and the degree of individual differences in the expectations of efficacy. Also, the previous experiences 
and achieving achievements in the previous tasks constitute a strong motivation and an internal stimulation towards success in similar tasks. They also suggested that self-efficacy mediates the relationship between problem-solving and the desire to solve those problems. (Bandura, 1989) suggested that expectations and perceptions affect the individual's behavior via selecting behavior and thinking method. Self-efficacy also defines the amount and rate of the exertion that the individual exerts during observing the performance of the targeted activity.

Accordingly, self-efficacy is viewed as an important personal variable. When it is linked with certain objectives and Performance, it contributes obviously in the future behavior; people determine their future and shape it according to their behavior, but not based on what will happen to them in a certain situation (Al Murad, 2008). The individuals who develop high self-efficacy are characterized by having the ability to achieve higher educational grades and better achievement. Also, the individual's efficacy helps him to generate actual self-capabilities that contribute to attain more learning and achievement; they do more efforts to eliminate obstacles and overcome challenges (Fahle et al., 2019).

The researcher reviewed the relevant studies that investigate the variables of the present studies, where they were directed in order according to the year, from the newest to the oldest.

The studies that addressed marital happiness ordered from the newest to the oldest:

(Demirel, 2019) His study dealt with identification the level of welfare and happiness among the married individuals who are members in physical fitness center. The study sample consisted of (599) spouses. Oxford scale for happiness was developed by (Hills and Arqyle). The results revealed that there are no variances in the scale of happiness Back to gender and marital status. The results revealed that there is a positive relationship between the level of happiness and recreational participation.

(Homead, 2019) refers in his study to identification the impact of emotional relationships on marital happiness and functional performance. The study sample consisted of (30) employees from Al-Quds University. The results revealed that there is a strong relationship between emotional expression and the level of marital happiness among them.

(Pinar \& Yildirim, 2018) In their studies, they aim to reveal the role of self-disclosure in the relationship between supporting spouses and their feeling of happiness and Satisfaction with their joint marital life. The study sample was formed from (549) spouses from the city of Ankara. The scale of marital life and the scale of self-disclosure were used. The results revealed that the spouses who disclose themselves more deeply are happier and more satisfied. They receive more support from their partners and have more conceptualization about the nature of their marital life.

2.

\subsection{The Results That Addressed Psychological Needs}

(Faust's et al., 2020) study came to determine the relationship between satisfying psychological needs and involvement in extra curriculum activities and programs. The study sample consisted of (18) participants. The results revealed that the individuals feel enjoyment and challenge in performing the program activities when they realize that these programs promote their psychological needs, such as independence, efficacy and relationships.

(Yunus \& Ali, 2019) were studying the effect of psychological needs and irrational beliefs $s$ in causing cyber bullying among adolescents. The study sample consisted of (849) students. The scale of irrational beliefs and the scale of psychological needs were used. The results revealed that Psychological needs, such as dominance, independence, success predicted the occurrence of cyber bullying.

(Ebersold, Rahm, \& Tobias, 2019) conducted a study which aimed at identifying the psychological mechanisms concerning the impact of self-support by the manager on the positive and negative aspects of teachers' welfare during the process of satisfying psychological needs. The study sample consisted of (49) teachers. The scale of life satisfaction and the scale of psychological needs were used. The results revealed that the need for independence affects positively on the individuals' life satisfaction, while depression mediated the relationship between negative impact and emotional exhaustion. The results revealed that the need for independence, depression and depression represented psychological processes with regard to understanding the way through which social context affects teacher's welfare.

In his studies (Jiang et al., 2019) helped learn the role of teachers' beliefs and emotional expressions role of teachers' beliefs and emotional expression in supporting the psychological needs of students. The results revealed that teachers' beliefs about their roles as teachers and caregivers reflect the expression of their obvious 
expectations related to taking care of students and caring about their feelings. The results showed that teachers' beliefs are concerned about students' confidence and encouraging them to self-initiation. Also, these beliefs are related to teachers' assessment for the unhealthy behaviors among students.

(Ford, Olsen, Jam, \& Urick, 2019) conducted a study which aimed to find out the way through which the leader's procedures can achieve positive results for the teachers by satisfying the psychological needs of teachers at the three levels: personal, organizational. The study sample consisted of (1500) individuals. The results revealed that the personal dimension (interaction between the manager and teacher) promoted organizational commitment among teachers. Also, the need to affiliate represented by establishing vocational relationships based on Knowledge of skills increases the effectiveness of performance and achievement.

In his study, (Sharon et al., 2018) presented the role of predictive power of psychological needs in promoting learning and adaptation among a sample of pharmacists. The scales of psychological needs, academic motivation, and the ability to learn were used. The results revealed that psychological needs predicted welfare, happiness and learning results.

(Avci \& Hassan, 2017) conducted a study entitled "psychological needs as a predictor of the perceived exhaustion levels among teachers". The study sample consisted of (498) male and female teachers. The scale of exhaustion and the scale of psychological needs were used. The results revealed that psychological needs don't differ based on gender. Also, the need to success, independence and dominance considerably predicted exhaustion.

\subsection{The Studies That Addressed Self-efficacy}

(Yilmaz \& Turan, 2020) conducted a study which aimed at describing the relationship between primary educational stage and the beliefs of self-efficacy among teachers. The study sample consisted of (484) teachers. The scales of self-efficacy and pre-service in teaching were use. The results revealed that the levels of self-efficacy among teachers before service in teaching were higher than in-service practice.

(Wang \& Tsai, 2020 ) conducted a study which aimed at determining the level and degree students are satisfied or depressed and the extent of their psychological needs to independence and efficacy during learning science as well as the relationship between psychological needs and self-efficacy. The study sample consisted of (392) male and female students from the secondary schools in Taiwan. The results revealed that the students whose psychological needs were satisfied have a higher self-efficacy in learning science. The results revealed that satisfying the psychological needs represented a positive factor in changing self-efficacy and that satisfying the needs of independence and efficacy represented a motivating power towards positive work.

(Cam et al., 2020) conducted a study which aimed at pinpointing the role of self-efficacy in the relationship between problem-solving and hope. The study sample consisted of (494) male and female students. The three scales of hope, problem-solving and self-efficacy were used. The results revealed that there is a high level of positive correlation between problem-solving, self-efficacy and hope, and that the relationship between problem-solving and hope appears by developing self-efficacy. The results revealed that the individuals who have high ability to solve problems have a high level of self-efficacy.

(Bayra, 2020) conducted a study which aimed at discovering the level of self-efficacy among the gifted students in technology. The study sample consisted of (1376) male and female students. The scale of technology and teaching and the scale of self-efficacy were used. The results revealed that the degree of self-efficacy among the study sample individuals was moderate and that there are no differences attributed to gender.

(Demr, 2020) conducted a study to elucidate the relationship between self-efficacy, work, satisfaction, organizational commitment and self-motivation. The number of participants in this study was 321 individuals. The results showed that self-efficacy increases when job satisfaction increases.

(Froiland et al., 2019) conducted a study which aimed at detecting the impact of the relationship between teacher and student with regard to satisfying the psychological needs and its correlation with the happy feelings. The number of participants in this sample was (961) male and female students. The results revealed that there is a positive relationship between satisfying the psychological needs and feeling happy, and that satisfying psychological needs mediate the relationship between teachers and students. The results showed that promoting the relationship between teachers and students is related to the ability to satisfy the psychological needs.

\subsection{The Studies That Addressed the Relationship Between Marital Happiness and Self-efficacy}

(Erol et al., 2019) study came to find out the relationship between self-efficacy and marital happiness among teachers, and the number of teachers participating in the study was (172) married. The three scales of marital 
happiness, self-efficacy, and partner were used. The results revealed that respecting the partner predicted self-efficacy. The results also revealed that there is a strong supportive relationship between marital happiness and partner respect; meaning that marital happiness is expected positively by the mutual respect between partners, and that self-efficacy predicts marital happiness.

3.

\subsection{The Study Problem and Questions}

The interest in studying the variables of positive psychology is considered as an international new trend that emerged in the light of the tremendous changes that began to appear in the contemporary communities, where the technological, economic and social continuous changes contributed to the emergence of daily life problems and increased the severity of family stressors. These changes imposed negative effects on spouses and threatened their marital life. This finding is consistent with (Huston et al., 2001), which revealed that the nature of the marital life affects the quality of the individual's life in general. Also, the confused marital life is a strong indicator for possibility of depression among spouses. Therefore, the increased levels of marital problems impede growth and adversely affect the desire to satisfy the psychological needs and self-efficacy, in that self-efficacy is considered as one of the most prominent components of healthy growth and one of the factors predicting the individual's achievement to his objectives.

Several studies investigated the relationship between marital happiness and several other variables; however, there is paucity in the studies that investigated the relationship between marital happiness, psychological needs and self-efficacy. Accordingly, this study aimed to explore the nature of the relationship between these variables (marital happiness, psychological needs and self-efficacy) by answering the following questions:

1. What are the most common psychological needs among the study sample individuals?

2. What is the degree of self-efficacy among the participants in the study sample?

3. What is the level of marital happiness of the study participants?

4. What is the percentage of variance that is explained by psychological needs and self-efficacy regarding the level of marital happiness among the study sample individuals?

The study importance lies in the important role of marital happiness in the family stability and protecting it from marital conflicts. It also provides the opportunity to direct the powers of spouses towards performing their basic roles effectively and positively. Also, the current study attempts to shed light on the factors affecting the achievement of marital happiness, which could be overlooked by some spouses.

The importance of the study also lies in the exerted efforts in developing positivism and their role in detecting some variables that could affect marital happiness. Due to the importance of the topic of psychological needs and self-efficacy in marital happiness in particular and in psychological health in general, understanding these variables needs studying and investigating them and requires that spouses should have a deeper understanding of their impact on the individual's life within the family.

The applied importance: the results of this study may provide the information upon which family and marital counselors can depend to help them comprehend the character of marital relationship and the elements affecting that. The current study also provides specialists with the necessary information that contribute to developing effective counseling programs that help improve marital relationships and achieve marital happiness. The study provides applicable arbitrated scales.

The study limits: The is exclusive for the wives practicing the profession of lawyer during (2019-2020). The results of the study are limited to the measurement instruments used in the study, including the scale of psychological needs, the scale of self-efficacy and the scale of marital happiness, as well as the employed procedures of validity and reliability and the statistical methods used to answer the study questions.

\section{Method}

The study methodology represented the study population and sample as well as the instruments used in the study, where the descriptive correlative predictive approach was used. The study population consisted of all the married female lawyers in Amman during the year (2019-2020), where we weren't able to get the exact number of the study population individuals as it is not available in the records of judicial department. The study sample consisted of (150) married female lawyers, who were chosen in the simple random way.

Second, the study instruments: the following scales were used for the purpose of this study: 


\subsection{The Scale of Psychological Needs}

The scale of psychological needs was developed based on the theoretical literature and the previous studies (e. g. Faust et al., 2020; Abu AlQasim, 2015; Al-Aqaqad, 2019; Wang, 2020; Ebersold et al., 2019). The initial version of the scale consisted of (25) items distributed to (4) basic dimensions: psychological safety, need to achievement, need to affiliation, need to respect. The indicators of the scale's validity were verified by two ways: First, content validity:

The scale, in its initial image that consisted of (25) items, was introduced to (10) arbitrators of those who are specialized in the domain of educational counseling, psychology, and assessment and measurement. In order to validate the extent of clarity of items, the belonging of each item to the dimension that it measures, and the accuracy of linguistic formulation the questionnaire's items. Adopting the scale items was based on an agreement ratio of (89\%) between arbitrators; therefore, some items were modified, while (5) items were deleted since the arbitrators agreed that they are not suitable for the dimensions of the scale.

Second, validity of the internal construct: the validity of the internal construct was verified by calculating the correlation coefficients of the total degree for each dimension of the dimensions of psychological needs with the overall degree of psychological needs based on the data of the exploratory sample that consisted of (40) individuals from the study population outside the study sample. Table 1 shows the results.

Table 1. The correlation of the dimensions of psychological needs with the total degree of the scale

\begin{tabular}{cc}
\hline Dimension & Correlation coefficient \\
\hline Psychological safety & $\mathbf{0 . 8 0 * *}$ \\
Need to achievement & $\mathbf{0 . 7 7 * *}$ \\
Need to belonging & $\mathbf{0 . 8 7 * *}$ \\
Need to respect & $\mathbf{0 . 9 1 * *}$ \\
\hline
\end{tabular}

Statistically significant at $(0.01)$

Table 1 showed that the correlation coefficients values of the dimensions of psychological needs scale with the total degree of the scale ranged between (0.77-0.91), which are statistically significant at (0.01); meaning that all the dimensions of the scale are statistically significant with the scale as a whole.

Also, the correlation coefficient for each item was calculated with the total degree of the dimension to which they belong. Table 2 shows the values of Pearson correlation coefficient between the degrees on the items and the total degree for the dimension to which they belong.

Table 2. The values of correlation coefficient of each item with the dimension to which they belong of psychological needs dimensions

\begin{tabular}{cccc}
\hline Item number & Correlation coefficient & Correlation coefficient & Item number \\
\hline $\mathbf{1}$ & $0.74 * *$ & 11 & $\mathbf{0 . 5 2} * *$ \\
$\mathbf{2}$ & $0.63 * *$ & 12 & $\mathbf{0 . 7 7} * *$ \\
$\mathbf{3}$ & $0.82 * *$ & 13 & $\mathbf{0 . 6 3} * *$ \\
$\mathbf{4}$ & $0.75 * *$ & 14 & $\mathbf{0 . 7 9} * *$ \\
$\mathbf{5}$ & $0.88^{* *}$ & 15 & $\mathbf{0 . 8 4} * *$ \\
$\mathbf{6}$ & $0.56^{*}$ & 16 & $\mathbf{0 . 6 7} * *$ \\
$\mathbf{7}$ & $0.70^{* *}$ & 17 & $\mathbf{0 . 9 1} * *$ \\
$\mathbf{8}$ & $0.59 *$ & 18 & $\mathbf{0 . 7 8} * *$ \\
$\mathbf{9}$ & $0.72 * *$ & 19 & $\mathbf{0 . 9 3} * *$ \\
$\mathbf{1 0}$ & $\mathbf{0 . 8 5} * *$ & $\mathbf{2 0}$ & $\mathbf{0 . 8 2} * *$ \\
\hline
\end{tabular}

*statistically significant at $(0.01)$

**statistically significant at $(0.05)$

Table 2 showed that all the correlation coefficients of items with the dimensions to which they belong were statistically significant and ranged between (0.52-0.93); meaning that the scale measures the psychological needs. Therefore, the final image of the scale consisted of (20) items.

The scale's reliability: the reliability of the scale was verified by using internal consistency (Cronbach alpha) as well as test re-test, where the scale was applied to an exploratory sample that consisted of (40) individuals with two weeks separating the two tests. Cronbach Alpha coefficient and Pearson correlation coefficients were calculated between the two applications for each dimension and for the scale as a whole. Table 3 shows the 
results of reliability according to the scale's dimensions.

Table 3. The value of reliability coefficient using Cronbach alpha and test re-test to the scale of psychological needs as a whole and each of its dimensions

\begin{tabular}{ccc}
\hline Dimension & Reliability coefficient (test re-test) & Reliability coefficient (Cronbach alpha) \\
\hline Psychological safety & $0.92 * *$ & 0.86 \\
Need to achievement & $0.85 * *$ & 0.90 \\
Need to belonging & $0.88 * *$ & 0.84 \\
Need to respect & $0.74 * *$ & 0.81 \\
The scale as a whole & $\mathbf{0 . 9 3}$ & $\mathbf{0 . 9 1}$ \\
\hline
\end{tabular}

**statistically significant at $(0.01)$

Table (3) shows that the scale has acceptable reliability degrees for the purposes of the current study, where the reliability coefficient was $(0.93)$ by using test re-test method, and (0.91) using internal consistency (Cronbach alpha), whereas the values of reliability coefficients on the dimensions of psychological needs scale ranged between (0.74-0.92) using test re-test, and the values of internal consistency coefficients for these dimensions ranged between $(0.81-0.90)$.

Scoring the scale of psychological needs:

Likert 5-point scale was used as follows: (always) $=5$ degrees; (frequently) $=4$ degrees; (occasionally) $=3$ degrees; (infrequently) $=2$ degrees; (never) $=1$ degree, while the scoring was the opposite way in the negative items.

The following standard was used to judge the item's degree: the highest value- the lowest value for the response alternatives divided on the number of levels $(5-1) \div 3=1.33$. This value equals the period length. Therefore, the values of means are: A- If the item mean is less than or equals (2.33). The score for the item is low.

If the item mean extends amongst (2.34- 3.67), then the item degree is medium. C- If the item mean ranges between (3.68- 5), this means that the score of the item is high. The degrees range between (20-100) degrees, where the low scores indicate a low level and the high scores indicate a high level of psychological needs.

\subsection{The Scale of Self-efficacy}

The scale of self-efficacy (Schwarzer \& Jerusalem) was used in its Arabic version for Samir Jamil Radwan (1997), who translated the scale from German language to Arabic language and applied to the university students from different faculties. The scale's validity was verified in its original version by calculating the internal consistency by the correlation coefficient between the degree in each item of the total ten items and the whole degree in the sample, where all Alpha values were more than $(0.80)$ and the overall correlation coefficient was (0.85). Also, the reliability of the scale in its original version was calculated using test re-test, as it was applied to a sample that consisted of (37) participants and ranged between (0.76-0.90).

The researcher performed the procedures of reliability and validity for the current study by introducing the scale in its initial form that consisted of (10) items to (10) arbitrators of those specialized in the domain of educational psychological counseling in the Jordanian Universities in order to verify the clarity of its items and the accuracy of linguistic formulation. An agreement of (80\%) amongst arbitrators was the standard for adopting items. Content validity was verified by applying the scale to a sample that consisted of (40) individuals from the study population, outside the study sample by calculating the correlation coefficients for the items of the scale with the total score of the scale. The correlation coefficients of the items with the scale as a whole ranged between (0.49-0.82).

Also, the reliability of the scale was verified by applying it to a sample that consisted of (40) individuals from the study population, outside the sample individuals, where reliability coefficient using test-retest method was (0.77). The reliability coefficient using the internal consistency (Cronbach alpha) was (0.85). The scale consisted of ten items rated as follows: $($ always $)=5$ degrees; $($ often $)=4$ degrees; $($ sometimes $)=3$ degrees; $($ rarely $)=2$ degrees; (never) $=1$ degree, while the scoring was the opposite way in the negative items. If the item mean is less than or equals (2.33), then the item degree is low. If the item mean ranges between (2.34-3.67), then the item degree is medium and if the item mean ranges between (3.68-5), then the item degree is high.

\subsection{The Scale of Marital Happiness}

Content validity: The scale in its initial form that consisted of (45) items was introduced to (10) arbitrators of those specialized in the domain of educational psychological counseling in order to prove the clarity of its items, 
the extent to which each item belongs to the remoteness that it measures and the accuracy and clarity of the wording of the sentences and vocabulary used. An agreement of (80\%) amongst arbitrators was the standard for adopting items; therefore some items were modified and five items were deleted for being in appropriate. Internal structure validity: structure validity was tested by calculating the connection coefficients of the total score for each of marital happiness dimensions with the complete score of marital happiness scale based on the information of a sample that consisted of (40) individuals from the study population, outside the sample individuals. Table (4) shows the results.

Table 4. The Correlation coefficients for marital happiness by removing it with the total score of the scale

\begin{tabular}{cc}
\hline Dimension & correlation coefficient \\
\hline Emotional psychological adjustment & $\mathbf{0 . 9 0 * *}$ \\
Family coherence & $\mathbf{0 . 8 7 * *}$ \\
Economic adjustment & $\mathbf{0 . 8 5 * *}$ \\
Social adjustment & $\mathbf{0 . 9 5 * *}$ \\
Intellectual adjustment & $\mathbf{0 . 7 8 * *}$ \\
\hline
\end{tabular}

** Statistical significance index at (0.01)

Table 4 explains that the correlation coefficients for marital happiness dimensions with the whole score of the scale stretched between (0.78- 0.95), which are statistically significant at $(0.01)$; meaning that all the dimensions of the scale are statistically significant with the scale in its entirety.

Also, the correlation coefficient for each item was calculated with the total degree of the dimension to which they belong. Table 5 shows the values of Pearson correlation coefficient between the degrees on the items and the total degree for the dimension to which they belong.

Table 5. The values of correlation coefficient of each item with the dimension to which they belong of psychological happiness dimensions

\begin{tabular}{cccccccc}
\hline $\begin{array}{c}\text { Item } \\
\text { number }\end{array}$ & $\begin{array}{c}\text { Correlation } \\
\text { coefficient }\end{array}$ & $\begin{array}{c}\text { Item } \\
\text { number }\end{array}$ & $\begin{array}{c}\text { Correlation } \\
\text { coefficient }\end{array}$ & $\begin{array}{c}\text { Item } \\
\text { number }\end{array}$ & $\begin{array}{c}\text { Correlation } \\
\text { coefficient }\end{array}$ & $\begin{array}{c}\text { Item } \\
\text { number }\end{array}$ & $\begin{array}{c}\text { Correlation } \\
\text { coefficient }\end{array}$ \\
\hline $\mathbf{1}$ & $0.70 * *$ & 11 & $0.67 * *$ & 21 & $0.81 * *$ & 31 & $0.88 *$ \\
$\mathbf{2}$ & $0.63 * *$ & 12 & $0.70 * *$ & 22 & $0.92 * *$ & 32 & $0.59 * *$ \\
$\mathbf{3}$ & $0.80 * *$ & 13 & $0.83 * *$ & 23 & $0.64 * *$ & 33 & $0.88 * *$ \\
$\mathbf{4}$ & $0.55 * *$ & 14 & $0.76 * *$ & 24 & $0.79 * *$ & 34 & $0.69 * *$ \\
$\mathbf{5}$ & $0.89 * *$ & 15 & $0.79 * *$ & 25 & $0.86 * *$ & 35 & $0.74 * *$ \\
$\mathbf{6}$ & $0.64 * *$ & 16 & $0.66 * *$ & 26 & $0.47 *$ & 36 & $0.85 * *$ \\
$\mathbf{7}$ & $0.88 * *$ & 17 & $0.87 * *$ & 27 & $0.56 * *$ & 37 & $0.60 * *$ \\
$\mathbf{8}$ & $0.73 *$ & 18 & $0.57 * *$ & 28 & $0.78 * *$ & 38 & $0.84 * *$ \\
$\mathbf{9}$ & $0.46 * *$ & 19 & $0.83 * *$ & 29 & $0.70 * *$ & 39 & $0.74 * *$ \\
$\mathbf{1 0}$ & $0.62 * *$ & 20 & $0.89 * *$ & 30 & $0.54 * *$ & 40 & $0.86 * *$ \\
\hline
\end{tabular}

*The degree of statistical significance at $(0.01)$

**Statistically significant at (0.05)

Table (5) showed that all the correlation coefficients of items with the dimensions to which they belong were statistically significant and ranged between (0.46-0.92), which at (0.01); meaning that the scale gauges marital happiness. Consequently, the ending image of the scale consisted of (40) items, which are distributed to five basic dimensions. The scale's reliability: Stability of scale was verified by using inner consistency (Cronbach alpha) as well as test re-test, where the scale was used on an exploratory sample that comprised of (40) individuals with two weeks separating between the two applications. Cronbach Alpha coefficient and Pearson correlation coefficients were analyzed between the two applications for each component and for the scale as a whole. Table 6 shows the consequences of reliability according to the scale's dimensions.

Table 6 shows that the scale has agreeable reliability marks for the objectives of the current research, where the reliability coefficient was $(0.92)$ by using test re-test method, and (0.89) employing internal consistency (Cronbach alpha), whereas the values of reliability coefficients on the dimensions of marital happiness scale ranged between (0.73-0.92) using test re-test, and the rates of internal consistency coefficients for these dimensions stretched between $(0.70-0.90)$. 
Table 6. The value of reliability coefficient using Cronbach alpha and test re-test to the scale of marital happiness as a whole and each of its dimensions

\begin{tabular}{ccc}
\hline Dimension & $\begin{array}{c}\text { Reliability coefficient (test } \\
\text { re-test) }\end{array}$ & Reliability coefficient (Cronbach alpha) \\
\hline Emotional psychological adjustment & $0.87^{* *}$ & 0.90 \\
Family coherence & $0.85 * *$ & 0.70 \\
Economic adjustment & $0.73 * *$ & 0.77 \\
Social adjustment & $0.92 * *$ & 0.88 \\
Intellectual adjustment & $0.82 * *$ & 0.85 \\
The scale as a whole & $0.92^{* *}$ & 0.89 \\
\hline
\end{tabular}

** statistically significant at $(0.01)$

Scoring the scale of marital happiness: Likert 5-point scale was used. If the item mean is less than or equals (2.33), then the item degree is low. If the item mean ranges between (2.34-3.67), then the element degree is average and if the item mean ranges between (3.68-5), then the element grades is high. The degrees range between (40-200) marks, where the low results signal a low level and the high scores signal a high level of marital happiness.

\section{Results}

The outcomes relating to the primary question and their discussion. What are the most common psychological needs among the study sample individuals?

So as to answer the question, the means and standard deviations were calculated

Table 7. The means, standard deviations, the rank and level for the dimensions of psychological needs

\begin{tabular}{ccccc}
\hline Dimension & Mean & SD & Rank & Level \\
\hline The need to achievement & 3.70 & 0.68 & 1 & High \\
The need to belonging & 3.66 & 0.59 & 2 & Medium \\
The need to respect & $\mathbf{3 . 5 4}$ & $\mathbf{0 . 4 7}$ & $\mathbf{3}$ & Medium \\
Need to psychological safety & $\mathbf{3 . 5 0}$ & $\mathbf{0 . 4 0}$ & $\mathbf{4}$ & Medium \\
\hline
\end{tabular}

Table 7 shows that the highest level of psychological needs was for the need to achievement, with a mean of (3.70) and a standard deviation of (0.68), followed by the need to belonging with a mean of (3.66) and a standard deviation of (0.59). The need to respect was in the third rank with a mean of (3.54) and a standard deviation of (0.47),while the need to psychological safety was in the last rank with a mean of (3.50) and a standard deviation of $(0.40)$.

The results relating to the second question. What is the level of self-efficacy among the study sample individuals?

In order to response the question, the means and standard deviations were calculated.

Table 8. The means, standard deviations for the level of self-efficacy

\begin{tabular}{cccc}
\hline Sample & Mean & standard deviations & Estimation level \\
\hline 150 & 3.82 & 0.69 & High \\
\hline
\end{tabular}

Table 8 shows that the level of self-efficacy among the study sample individuals was high, with a mean of (3.82).

The results relating to the third question. What is the level of marital happiness among the study sample individuals?

In order to answer the question, the means and standard deviations were calculated.

Table 9 shows that the level of marital happiness was medium, with a mean of (3.66) and a standard deviation of (0.62). The highest level of marital happiness was for family coherence with a mean of (3.87) and a standard deviation of (0.82). The dimension of social adjustment was in the second rank with a mean of (3.65). 
Table 9. The means, standard deviations, the rank and level for the dimensions of marital happiness

\begin{tabular}{ccccc}
\hline Dimension & Mean & SD & Rank & Level \\
\hline Family coherence & 3.87 & 0.82 & 1 & Medium \\
Social adjustment & 3.65 & 0.77 & 2 & Medium \\
Intellectual adjustment & 3.61 & 0.72 & 3 & Medium \\
Psychological and emotional adjustment & 3.56 & 0.70 & 4 & Medium \\
economic adjustment & 3.50 & 0.68 & 5 & Medium \\
The total score & $\mathbf{3 . 6 6}$ & $\mathbf{0 . 6 2}$ & & \\
\hline
\end{tabular}

The fourth question: What is the percentage of variance that is explained by psychological needs and self-efficacy regarding the level of marital happiness among the study sample individuals?

In order to answer the question, the direct relationships were investigated between variables. Table 10 shows the results.

Table 10. The direct relationships between the model variables

\begin{tabular}{ccccccc}
\hline Variables & Dimension & Estimation & $\begin{array}{c}\text { Standard route } \\
\text { coefficient }\end{array}$ & $\begin{array}{c}\text { Standard } \\
\text { error }\end{array}$ & $\begin{array}{c}\text { t- } \\
\text { value }\end{array}$ & $\begin{array}{c}\text { Sig } \\
\text { level }\end{array}$ \\
\hline Psychological needs & Psychological safety & 0.93 & 0.41 & 0.87 & 6.00 & $* * * * *$ \\
Self-efficacy & & 0.90 & 0.36 & 0.84 & 6.10 & $* * * * *$ \\
\hline
\end{tabular}

Table 10 shows that there is a direct effect for the need of psychological safety marital happiness, where the value of the standard route was (0.87) and t-value was (6.00). The results revealed that there is an impact for self-efficacy on marital happiness, where the value of standard route was (0.87), and a t-value of (6.10).

\section{Discussion}

The results revealed that the most common psychological needs were related to the need to achieve, then the need to belonging. The need to achievement is attributed to the increased life demands and challenges facing wives at the personal and professional level which affect the level of achievement; this was confirmed by (Mattew \& Rodin, 2002), which suggested that taking the responsibilities of marriage and family requirements as well as doing the required job tasks at work imposes more pressure on the wife, in terms of creating more marital difficulties and affecting the levels of achievement. The need to belonging is represented by the desire of making social relationships that are based on love and friendship which, in turn, represents an important aspect of understanding the individuals' psychology. This need emerges as a result of the requirements and responsibilities imposed by their jobs, along with the tasks of housework and taking care of children; these activities are performed at the expense of the time of social relationships, where they have no time to discuss their objectives, challenges and viewpoints about intellectual and life issues with others in order to satisfy their need of belonging. This agrees with (Belanger, et al., 2014), who suggested that the individual's ability to establish social relationships and make sacrifice is considered as one of the main factors for achieving social adjustment, where the psychological health is mainly determined by the individual's strong relationships with the surrounding environment (family, friends) and the extent of harmony in these relationships. (Batool \& Khalid, 2012) suggested that happiness lies in satisfying the needs related to the important family issues.

The outcomes exhibited that the level of self-efficacy among the study sample individuals was high. This is attributed to the nature of marital relationship which provides the wife with the feeling of value and importance; that is reflected by participation in decision-making, the ability to deal positively with problems and the successful management of work. These factors primarily determine the solidity of self-efficacy, promote positive interaction, establish healthy personality and create the power of achievement and innovation at the personal and professional levels. This finding agrees with (Demr, 2020), who suggested that high self-efficacy promotes job satisfaction. It also matches with (Yilmaz \& Turan, 2020) and (Wang \& Tasi, 2020).

The level of marital happiness among the study sample individuals was medium on the total degree. This is attributed to the marital relationship that satisfies the ambition of wives, promotes the positive interaction between spouses and enables them to deal effectively with the problem facing them; where these characteristics enhance the achievement of marital happiness. This finding agrees with Chen, Tanaka, Uji (2007) which revealed that marital happiness is based on basic components that enable the spouses to develop their personal traits in the light of the mutual respect and sacrifice, in addition to developing their ability to take the 
responsibility of marriage and solve the problems they are facing. moreover, (Bouchard et al., 1999) confirmed that being committed to the requirements of marital life and achieving harmony in the marital relationship, is one of the basic factors for marital happiness.

The results confirmed the impact of the dimension of psychological needs on achieving marital happiness. This finding agrees with a number of studies that asserted the importance of satisfying the psychological needs in achieving marital happiness, including (Froiland, Worrell, \& Frank, 2019) who suggested that there is a positive relationship between satisfying the psychological needs and the sensation of happiness. The results also match with (Sharon et al., 2018), who suggested that psychological needs predicted the achievement of welfare and happiness among the study sample individuals.

(Liu, 2019) confirmed that psychological needs have a basic role in promoting individuals to participate in the various domains of life and achieve a high level of happiness and satisfaction. The results also revealed the impact of self-efficacy on achieving marital happiness, where the happy people enjoy a high degree of self-efficacy and they are more satisfied with themselves. They also exert more effort in performing their different activities, in that such individuals are characterized by their high ability to organize and direct themselves towards their objectives. This finding agrees with (Erol et al., 2019), suggesting that self-efficacy predicts marital happiness.

\section{Recommendations}

1- In the light of the importance of the positive variables in marital life, the study recommend conducting more experimental researches in the domain of marital happiness and self-efficacy by developing Counseling Programs capable of improving these variables among spouses in the different domains and work sectors.

2- Promoting the role of media in promoting self-efficacy among individuals.

\section{References}

Avci, A., \& Hasan, K. (2017). Psychological Needs as the Predictor of Teachers Perceived Stress Levels. Journal of Education Training Studies, 5(4), 154-164. https://doi.org/10.11114/jets.v5i4.2274

Basharpoor, S., \& Sheykholeslami, A. (2015). The Relation of Marital Adjustment and Family Functions with Quality of Life in Women. Journal of Psychology, 11(3), 432-441. https://doi:10.5964/ejop.v11i3.859

Al-Jaberi, M. (2012). Internet addiction and its relationship with psychological needs among the high school students (Unpublished Master Thesis). The University of Teeba, AlMedina AlMonawwara, Saudi Arabia.

Bayra, E. (2020). Gifted Students Self-Efficacy of Educational Techology for Technology and Design. Journal of Educational and Instructional Studies in the World, 10(1), 1-17.

Bélanger, C. et al. (2014). Self-Esteem, Coping Efforts and Marital Adjustment. Europe's Journal of Psychology, 10(4), 660-671.

Bosaisini, H. (2011). Seperation anxiety among kindergarten kids and its relationship with parents' marital adjustment (Unpublished Master Thesis). The University of Damascus, Damascus, Syria.

Bouchard, G. (2006). Cohabitation Versus Marriage: The Role of Dyadic Adjustment in Relationship Dissolution. Journal of Divorce \& Remarriage, 46(1), 107-117.

Cam, Z. et al. (2020). The Mediating Role of Self- Efficacy in the Relationship Between Problem Solving and Hope. Particpatory Educational Research, 7(1), 47-58. https://doi.org/10.17275/per.20.4.7.1

Camisasca, E. et al. (2014). Is the Relationship Between Marital Adjustment and Parenting Stress Mediated or Moderated by Parenting Alliance? Europes Journal of Psychology, 10(2), 235-254.

Chaing, L. (2010). The development of A Leisure and life satisfaction Scalefor outpatient (Lissop) Leisure activity programs in Iowa (Doctoral Dissertation submitted in partial fulfillment to the office of Graduate studies of university of Northern Iowa).

Chen, Z. et al. (2007). The Role of Personalities in the Marital Adjustment of Japanese Couples. Social Behavior and Personality, 35(4), 561-572. https://doi.org/10.2224/sbp.2007.35.4.561

Cihangir Cankaya, Z. (2020). An Explanation of Happiness with Secure Attachment, Basic Psychological Needs and Hope: The Case of Turkish University Students. European Journal of Educational Research, 9(1), 433-444.

Daniel, Be. et al. (2013). Prospective associations between marital adjustment and life satisfaction, Personal 
Relationships, (20), 728-739. https://doi.org/10.1111/pere.12011

Deci, E. et al. (2001). Need Satisfaction motivation And Well-being in the work organization USA. Journal of Personality and social psychology. https://doi.org/10.1177/0146167201278002

Demirel, M. (2019). Leisure Involvement and Happiness Levels of Individuals Having Fitness Center Membership. Journal of Education and Learning, 8(6), 140-149. https://doi.org/10.5539/jel.v8n6p140

Demr, S. (2020). The Role of self-Efficacy in Job Satisfaction Organizational Commitment, Motivation and Job Involvement. Eurasian Journal of Educational Research, (85), 205-224.

Diener, E. (2000). Subjective Well-Being: The Science of Happiness and a Proposal for a National Index. American Psychologist, (55), 34-43. https://doi.org/10.1037/0003-066X.55.1.34

Easterlin, R. (2001). Life Cycle Welfare: Evidence and Conjecture. Journal of Socio-Economic, 30(1), 31-61.

Ebersold, S., Rahm, T., \& Heise, E. (2019). Autonomy support and well-being in teachers: Differential mediations through basic psychological need satisfaction and frustration. Social Psychology of Education, 22, 921-942. https://doi.org/10.1007/s11218-019-09499-1

Erol, U. et al. (2019). Subjective Vitality Mediates the Relationship between Respect to word Partner and Subjective Happiness on Teachers. Universal Journal of Educational Research, 7(1), 126-132. https://doi.org/10.13189/ujer.2019.070117

Homed, H. (2019). Emotional Relationships and Their Relationship to Marital Happiness and Their Impact on Job Performance Field Study. International Journal of Academic Pedagogical Research, 3(2), 7-24.

Schramm, D. et al. (2012). Religiosity Homogamy, and Marital Adjustment: An Examination of Newlyweds in First Marriages and Remarriages. J. of Family, 33(2), 246-268. https://doi.org/10.1177/0192513X11420370

Schwarzer, R., \& Jerusalem, M. (1995). Generalized Self-Efficacy Scale. In J. Weinman, S. Wright, \& M. Johnston, Measures in Health Psychology: A Users Portfolio. Causal and Control Beliefs, 33-37.

Sharon, T. et al. (2018). How Basic Psychological Need and Motivation Affect Vitality and Lifelong Learning Adaptability of Pharmacists: A Structural Equation Model. Advances in Health Sciences Education, 33(3), 549-566.

Shigeto, A. et al. (2014). Roles Of Family Cohesiveness, Marital Adjustment, And Child Temperament In Predicting Child Behavior With Mothers And Fathers. Journal of Social and Personal Relationships, 31(2), 200-220. https://doi.org/10.1177/0265407513490586

Kamp Dush, C. et al. (2008). Marital Happiness and Psychological Well-Being across the Life Course. Family Relations, 57(2), 211-226. https://doi.org/10.1111/j.1741-3729.2008.00495.x

Pinar, C., \& Yildirim, I. (2018). The Mediator Role of Spousal Self-Disclosure in the Relationship Between Marital Satisfaction And Spousal Support. Educational Sciences: Theory and Practice, 18(2), 701-736. https://doi.org/ 10.12738/estp.2018.3.0086

Faust, L., \& Kuperminc, G. (2020). Psychological Needs Fulfillment and Engagement in After School: "I pay Attention Because I Am Really Enjoying This". Journal of Adolescent Research, 35(2), 201-224. https://doi.org/10.1177/0743558419852058

Froiland, J. et al. (2019). Teacher Student Relationship, Psychological Need Satisfaction, and Happiness Among Diverse Students. Psychology in the Schools, 56(5), 856-870. https://doi.org/10.1002/pits.22245

Ford, T. et al. (2019). The Effects of Leader Support for Teacher Psychological Needs on Teacher Burnout, Commitment and Intent to Leave. Journal of Education Administration, 57(6), 615-634. https://doi.org/10.1108/JEA-09-2018-0185

Furdyna, H. et al. (2008). Relative Spousal Earnings and Marital Happiness among African American and White Women, Journal of Marriage and Family, $332-344$. https://doi.org/10.1111/j.1741-3737.2008.00485.x

Jiang, J. et al. (2019). Teacher Beliefs and Emotion Expression in Light of Support for Student Psychological Needs: A Qualitative Study. Education Sciences, 9(68), 21-25. https://doi.org/10.3390/educsci9020068

Kalatbari, J. et al. (2013). The Relationship between Marital Satisfaction (Based on Religious Criteria) and Emotional Stability. Social and Behavioral Sciences, 849-873. https://doi.org/10.1016/j.sbspro.2013.06.664 
Kalkan, M., \& Ersanli, E. (2008). The Effects of the Marring Enrichment Program Based on the CognitiveBehavioral Approach on the Marital Adjustment of Couples. Educational Sciences: Theory \& Practice, 8(3), 977-986.

Khodarahimi, S. (2015). The Role of Marital Status in Emotional Intelligence Happiness, Optimism and Hope. Journal of Comparative Family Studies, 46(3), 351-371. https://doi.org/10.3138/jcfs.46.3.351

Kumar, S. (2015). Psychological Well Being and Marital Adjustment: A Study on Elderly Couples in Post Parental Stage of Life. Indian Journal of Gerontology, 29(1), 77-90.

Moamari, N., \& Khalidi, Y. (2014). Adolescent Perception of the Degree of Satisfaction of his Parents to His Psychological Needs: A Psychological Study on a Sample of Adolescents Schooling in Some Modes of Ouargla and Its Suburbs (Unpublished Master Thesis). Qasidi Merbah University, Algeria.

Moosavi, S., \& Iravani, M. (2012). A Study on Relationship between Emotional Maturity and Marital Satisfaction. Management Science Letters, 2(3), 927-932. https://doi.org/10.5267/j.msl.2011.10.012

Muraru, A., \& Turliuc, M. (2013). Predictors of Marital Adjustment: Are There Any Differences Between Women and Men. Europe's Journal of Psychology, 9(3), 427-442.

Pasch, L., \& Bradbury, T (1998), Social Support, Conflict, and the Development of Marital Dysfunction, Journal of Consulting and Clinical Psychology, 66(2), 219-230. https://doi.org/10.1037/0022-006X.66.2.219

Yilmaz, D., \& Turan, H. (2020). Self-Efficacy Beliefs of Pre-Service Teachers in Teaching First Reading and Writing and Mathematics. Participatory Educational Research, 7(1), 257-270. https://doi.org/10.17275/per.20.15.7.1

Yunus, S., \& Ali, C. (2019). The Relationship between Irrational Beliefs, Resilience, Psychological Needs, Cyberbullying and Cyber Victimization. Universal Journal of Educational Research, 7(3), 700-706. https://doi.org/10.13189/ujer.2019.070308

Wang, Y. et al. (2020). An Investigation of Taiwanese High School Students Basic Psychological Need Satisfaction and Frustration in Science Learning Contexts in Relation to Their Science Learning Self-Efficacy. International Journal of Science and Mathematics Education, 18(1), 43-55.

\section{Copyrights}

Copyright for this article is retained by the author(s), with first publication rights granted to the journal.

This is an open-access article distributed under the terms and conditions of the Creative Commons Attribution license (http://creativecommons.org/licenses/by/4.0/). 